\title{
Prominente Patienten
}

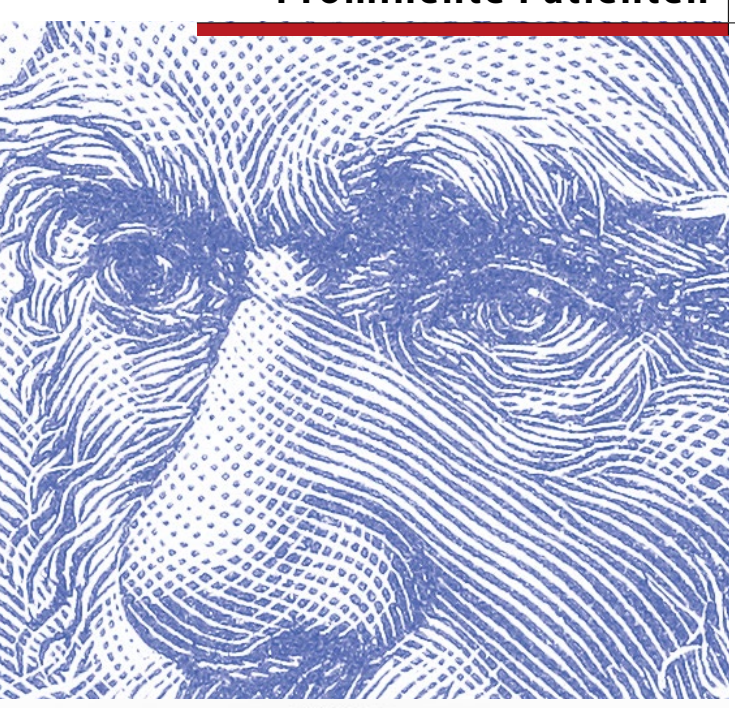

\section{Würgen, Lumbago, Depression}

\section{Charles Darwin}

\author{
Über Charles Darwins (1809-1882) mysteriöse Krankheit ist seit Jahr- \\ zehnten spekuliert worden. Die Auswahl der möglichen Diagnosen \\ reicht von Neurosen und multiplen Allergien bis zu Morbus Crohn.
}

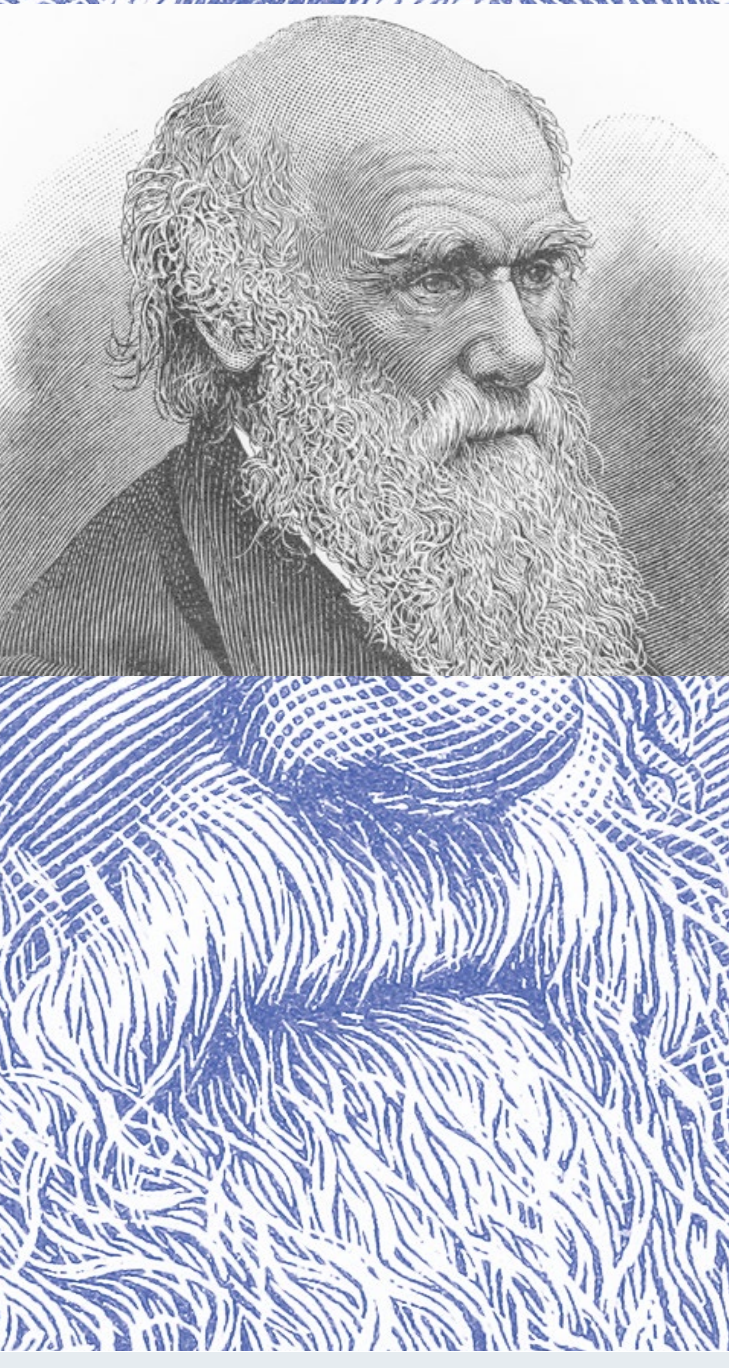

Prominente Patienten

Wussten Sie, warum Warhol stets grüne Baumwollunterwäsche trug? Was es mit dem „Einstein Sign“ auf sich hat? Und weshalb Schiller an der Fertigstellung von Goethes Faust zweifelte? Schauen Sie mit uns in die Krankenakten berühmter Persönlichkeiten.
E ine Tropenkrankheit hätte sich Charles Darwin während seiner fünfjährigen Reise mit der „H.M.S. Beagle" natürlich auch zuziehen können. Prof. Saul Adler von der Hebrew University in Jerusalem vermutete 1959 in der Zeitschrift „Nature“, er habe sich aus Argentinien die Chagas-Krankheit mitgebracht, die südamerikanische Trypanosomiasis. Doch die Krankheit verläuft meistens symptomlos.

Das spricht gegen Chagas-Krankheit: Der Tropenmediziner Prof. A. W. Woodruff bestritt bereits 1965 den Zusammenhang mit einer Trypanosomen-Infektion, vor allem weil viele auch später häufige Symptome Darwins wie Palpitationen, Erschöpfung, Übelkeit, zitternde Hände und Dermatitis bereits vor Antritt der Weltreise bei dem 22-Jährigen vorhanden gewesen seien. Die sehr variablen Symptome, ihr unregelmäßiges Auftreten, das verhältnismäßig lange Leben Darwins sowie die Verbesserung der Zustände unter Therapien, denen wir heute eher eine Placebo-Wirkung zuschreiben würden, sprächen bevorzugt für eine neurotische Störung, meinten Woodruff und Mitarbeiter.

Doch die Hypothese wird nicht kritiklos geteilt. Besonders die in Darwins Briefen beschriebenen schweren Attacken der Krankheit und die verzweifelten Versuche, seine Arbeit trotzdem fortzusetzen, lassen die Vorstellung, Darwin habe Brechattacken provoziert, nur um nicht zu Dinnerpartys gehen zu müssen, absurd erscheinen. Darwins Appetit war meist gut, sein Körpergewicht stabil. Der Brite Dr. D. A. B. Young weist auf viele Details der Krankheitsausbrüche hin, etwa eine Anämie sowie anfallsartig auftretende Ekzeme und Erytheme im Kopfbereich, oft verbunden mit gastrointestinalen Symptomen. Hinzu kamen Taubheitsgefühl in Fingerkuppen und gichtartige Arthralgien.

Lupus oder M. Crohn: Nach Youngs Meinung spricht einiges für einen systemischen Lupus erythematodes (SLE), $\mathrm{z}$. B. auch die akuten, fieberhaften Reaktionen auf starke Sonnenexposition und heiße Umgebung während der BeagleExpedition. Andere gehen von einer systemischen Laktoseintoleranz Darwins aus. Zwei chilenische Ärzte kommen zu dem Schluss, Darwin habe an Morbus Crohn gelitten. Die Krankheit sei vor allem im oberen Dünndarm lokalisiert gewesen, meinen Dr. Fernando Orrego und Dr. Carlos Quintana aus Santiago. Dies würde die oberen Abdominalschmerzen, die Flatulenz und das Erbrechen ebenso erklären wie die Gelenkund neurologischen Beschwerden, das Fatigue-Syndrom, vor allem aber den chronisch-rezidivierenden Verlauf. Die Hypothese einer chronischen Entzündung im oberen Dünndarmabschnitt würde die fehlende Diarrhö und die später auftretende Obstipation stützen. Etwa 8\% der Crohn-Patienten haben zudem aphthöse Ulzerationen im Mund, was bei Darwin ebenfalls der Fall war. Die tauben Fingerkuppen und brennende Schmerzen der Hände führen die Chilenen auf periphere Neuropathie zurück. Auch die Anämie und die gelbliche Hautfarbe passen in das Muster. Keine Erklärung haben Orrego und Quintana für die dermatologischen Befunde. Darwins (fehlende) Gesundheit bleibt mysteriös.

(TM) 